\title{
Study of Establishment and Optimization of the Sales Team
}

\author{
Meige Liu ${ }^{1}$ \\ ${ }^{1}$ Shaanxi Institute of International Trade \& Commerce, Xianyang, Shaanxi, 712046
}

KEYWORDS: Sales Team Construction; Team Market Ability; Motivation Method

\begin{abstract}
As enterprises increasingly competitive, business executives are deeply sluggish sales will bring a series of crises. Poor product sales, in addition to the product itself and the merits of the sales team are also very important. As the company's "blood", sales team management is a top priority, but a common problem is that although many companies pay attention to sales management, but most inexperienced sales manager, sales management is not professional, so there is no professional management and processes, resulting in many problems affecting the sales of sustainable development of enterprises is very negative.
\end{abstract}

\section{Introduction}

Team is a group of organizations, groups, distinguished Chinese and foreign researchers from the perspective of the role of the team or team behavior, respectively, they have been defined. "Parent Team Role Theory" • Meredith Belbin team means that the limited number of people for a common goal and work together, everyone assume different roles, a unique contribution. He also believes that a well organized team should not be too large, so that the team repeated the role or roles to generate competition and dysfunctional behavior. He believes community refers to a common goal of a certain number of people, because these people were so many people can not press relations team roles to form. P - Stephen Robbins definition of team is based on group definitions on the distinction. It means a group of two or more interacting and interdependent individuals, in order to achieve a specific target and the composition of aggregate. It can be formal, it can be informal. The team belongs to the formal group, which is one kind of formal group in order to achieve a goal of mutual cooperation by the individual composition. In the team, can produce positive synergies through the joint efforts of team members, team members make the results of its performance level is much greater than the sum of the individual members of the team performance. But there is no positive synergy in the group, their performance is only the sum of the individual contributions of each member. This definition highlights the team can not be equated to the concept of the general population, only formal group can be called a team.

\section{The Current Status of Domestic Enterprise Sales Team}

Currently, the presence of each company's sales team in a lot of issues that affecting the business performance. It can be divided into the following categories:

First, the efficiency is low. There are four cases salespeople often make the sales manager a headache: attendance not works and does not contribute labor; contribute not live; no interest in live. Simply put, it is this: While the sales staff attendance, but may be in the enterprise in the market or hotel; although sales staff visiting clients in the market, but the visit is very low efficiency, may one day visit only one or two customers; some sales staff, although very diligent, visiting more than a dozen customers every day, but the turnover rate is very low, only efficiency, to no avail, only hard 
work, elbow grease, fatigue, but no credit; some sales staff, although sales of large, but the turnover lower prices or sells low-margin products, reimbursement rate.

Second, the team instability. Cohesion sales staff, poor loyalty, sales force instability. People in and out frequently, hard to find sales staff, sales personnel instability, the sales staff is difficult to culture, these issues have increasingly become the bottleneck operation of the company, a sales staff train as many as six months, at least two or three months, during which enterprises continue selection, elimination, re-election, and then phased out, spend a lot of time, energy and resources, in the face of increasingly fierce competition, companies can shorten the manufacturing process if the sales staff in order to enhance the competitiveness of manufacturing sales staff in the end how long? How long can be shortened? Can a month will be able to reach a mature position? These problems have even become a strategic issue for enterprise development.

Third, the lack of personnel. Good salesman and sales managers are scarce ideal. Sales skills and capabilities, mainly for lack of expertise of the sales staff, sales team, sales skills and capacity needs to be improved.

Fourth, poor rampant. Staff narcissism, everyone thinks he is the company's largest art who always narcissism. Because of pride on their deep understanding of the product, or proud of myself to win orders between wine on the table laughing, or proud to be proficient in a number of other tricks, so there has been this first phenomenon. Driven by these ideas, sales people think of killing themselves is a natural thing. Because enterprises lack effective sales force management and control, which makes their idea gradually changes, so many negative things and negative rise, eventually leading to a problem such as sales staff took a vicious customers like. Therefore, the reasons not entirely to blame these people behind multidimensional, including the reasons, because the structure of management control processes, usually including a lack of appropriate counseling and evaluation of reasons.

\section{Sales Team Building Strategy}

The so-called no weak soldiers are forcing men, no unqualified soldiers, but unqualified marshal. A strong manager is primarily regulations-makers. Good rules and regulations, the implementation of those rules and regulations could feel the presence, but do not think the rules and regulations is a constraint. A top manager of the store, although regulations makers or supervisor, but should become an exemplary regulatory compliance. If itself is difficult to comply with, the requirements of the team members is much hard.

Team in different roles since the angle of view of the status and different goals and expectations of the work will be a great difference, which is not surprising. Then the manager asked us to be good at capturing different mindset among employees, understand their needs and help them to establish a common goal. Make an effort to make the team's efforts to form a joint force. Store managers can give employees plan a good development prospects and personal development plans, and make coordination and team goals. So that the team members clearly understand the great significance of the team to achieve the goals and objectives contained. Then the work of supervision and training of relevant job skills, so that team members have the basic skills to achieve the desired goals, and be able to good cooperation. The final step is to maintain a good working atmosphere, and if the team lacks proactive, united and progressive work atmosphere, it is difficult to force the team of employees together, we try to shift blame wrangling with each other, it will not succeed.

The company there are always some employees, intrigue, if not rectify the clean-up, over time, the team will only contain each group, there is no productive employees. As a store manager, in order to create a good atmosphere, these efforts need to do: penalties and rewards fair, the work of 
outstanding achievements who must make their psychoactive substances double harvest, labor does not contribute to those given appropriate punishment; each employee take some of the pressure that managers should not become "All the suffering, all tired, I have had to bear alone," the typical, as our managers more easily, indicating the more management in place; discussion on professional issues, to democratic equality, not to engage in one-man tyrants learn to fully mobilize the enthusiasm of each member; in life, we need more and more concerned about the care team, so that everyone can feel the warmth of the team.

The initial establishment of the store team work phases: from the idea stage to straighten out the confusion. No significant increase in the performance pressure, interactions between team members become familiar with the company's performance in the store processes, and business projects, but also the performance of everyone in the team to help each dutifully working hard and diligently to improve professional skills. But team members do not actually real or ideal method and there is no clear common purpose or performance goal. Main features: Team members from different motivations, needs and characteristics of the members, the lack of a common goal at this stage, the relationship between them has not been established, lack of understanding and trust between people, is still being run-in, team had established norms, rules or for not yet formed a common vision, then a lot of contradictions, a great internal friction, consistency rarely spend a lot of effort, not an effect. At this stage to take control type leadership style, not laissez-faire, the target established by the leader (but reasonable), clearly and immediately inform the team members their ideas and purpose and can not let members of their own imagination or guess, or easy-aliasing. Relations to emphasize the mutual support and help each other, the relationship between the people of this period is not yet stable, and therefore can not be too honest. This period should quickly establish the necessary specifications, do not need to be perfect, but need to be able to make the team to enter the track as soon as possible. At this provision can not be too much too cumbersome, otherwise difficult to understand, will lead to stumbling hand stumbling. Do the right thing is always better than doing things right. Establish team goals can be implemented to meet the needs principle: specific, measurable, achievable, relevant, and with a clear deadline.

Continue to develop as a potential complementary team stages: Stage start generating consensus and active participation. There are ever-increasing customer base and the corresponding pressure to perform. Interaction between team members offset the individual performance of each member and the sum of the whole is less than the sum of individual potential. Members requested that a relatively clear objectives, targets or workload, but also demand more constraints to form a common working methods and workflow. Main features: After a period of time, the idea of getting to know the team members and the team's goals leader, but also with each other via a familiar and generate understanding, for the team to understand the rules gradually, gradually reduce offending matter. If there are new employees, it must integrate into the team as soon as possible. Part team members can participate in decision-making, but in the gradual process of authorization, to maintain control while not all of a sudden put too much, otherwise it will lead to the recovery of power demoralized. With training is a very important thing in this period.

Forming sales team, it is truly complementary stages: Team members can openly express opinions different stages.

There are significant performance and performance evaluation of incremental pressure, and indeed the team to improve its performance as the core, complementary skills among members willing to common goals, objectives and methods of work and trust responsible, solidarity, work hard. Main features: As a leader in efforts to form an open atmosphere, allowing members to different opinions and views, even encourage constructive conflict, goal setting into a team leader 
by a common idea, regulated by external restrictions, variable internal commitment to team members during this period to become one, willing to sacrifice for the team, wisdom and creative juices flowing. At this time leaders must participate in the creation of an environment, and lead by example, allow the differences between different voices, while there will be initial confusion, many leaders fear chaos, again controlled, can lead to undesirable consequences, then you can use some effective establishing a common management team learning atmosphere, effectively ride out the storm.

\section{Conclusion}

Strengthen the sales force management can provide back-up marketing and management talent for the enterprise. Good business has a wealth of theoretical knowledge and practical experience, has been particularly familiar with their products and marketing network, enterprise when needed some good business promotion, added to the senior marketing management positions up, so that both inspire other business people, but it will soon be competent marketing management, marketing personnel so that enterprises in a virtuous circle.

\section{Reference:}

[1] William L. Crone, Industrial salesperson development: A career stages perspective Journal of Marketing, 1984 (48):. 41-52.

[2] Dana James "Incentive Programs Move to Cyberspace." Marketing News, December, 2000 (4): 16-20.

[3] R.K.Teas J.C. McElroy, Causal attributions and expectancy estimates: A framework for understanding the dynamics of sales force motivation Journal of Marketing, 1986 (50):. 70-81.

[4] Gordon J .Bad Vick, far rand J. Headway, and Peter F .Kaminski, Attributions and emotions:. The Effects on salesperson motivation after successful vs. unsuccessful quota performance Journal of Personal Selling \& Sales Management, 1992 (12): 1-11. 